\title{
Eosinophilic infiltrates of the gastrointestinal tract
}

\author{
AJ BLACKSHAW, * DA LEVISON $\dagger$ \\ From the Departments of Histopathology, ${ }^{*}$ Bedford General Hospital, Bedford, and $\dagger$ St Bartholomew's \\ Hospital, London
}

SUMMARY There are two lesions which are often confused despite their quite distinct clinical and pathological differences: the inflammatory fibroid polyp and eosinophilic gastroenteritis. Other eosinophilic lesions likely to be encountered in the gut also pose problems of differential diagnosis.

Eosinophilic infiltration, localised or diffuse, of the gastrointestinal tract cannot be regarded as a definitive diagnosis; neither can a classification of disease, in which this is a feature, be founded on the degree or site of such infiltration. Eosinophilia is merely a manifestation of inflammation, often with an allergic basis, and accompanies a number of well defined clinicopathological conditions, some of which have a known cause-for example, parasitic infestation-but most of which do not.

Eosinophils are normally present in the lamina propria of the gut mucosa, and there is no generally agreed number which is pathological. Groups of eosinophils are not normally found in the submucosa, muscle coat, or serosa. The common diagnostic dilemma, however, is not "are there increased numbers of eosinophils present in this lesion?" but rather, "what is the pathological importance of the eosinophilic infiltrate in this lesion?" An eosinophilic infiltrate in the bowel may either point to the nature of the underlying condition or may obscure it, and the confusing studies on the subject reflect the diagnostic, conceptual, and terminological difficulties entailed.

The name of eosinophilic granuloma has been applied to at least two primary gut conditions. Although the authors who originally described these conditions were careful to distinguish them clinically and pathologically from eosinophilic granuloma of bone (histiocytosis X), the continued use of the term has led to confusion. This confusion is exacerbated by the fact that the two gut entities so named are very different and can clearly be separated from each other pathologically, and to some extent, clinically. These

Accepted for publication 10 September 1985 are probably best described as the inflammatory fibroid polyp and eosinophilic gastroenteritis: eosinophilic granuloma is not recommended as terminology for lesions of the alimentary tract.

INFLAMMATORY FIBROID POLYP 12

The lesion has been called many things including: gastric fibroma with eosinophilic infiltration ${ }^{3}$; inflammatory pseudo-tumour ${ }^{45}$; (localised) eosinophilic granuloma ${ }^{6}$; haemangiopericytoma ${ }^{7}$; neurofibroma ${ }^{8}$; submucosal granuloma. ${ }^{9}$ An inflammatory fibroid polyp is a solitary polypoid or sessile lesion with an inflammatory basis. It is found in all age groups, although not often in children, and its maximal incidence is in the sixth decade (Table). The largest recently reported series of 64 cases $^{2}$ did not present age details in such a way as to permit their inclusion in our Table, but found a mean age of $48 \cdot 8$ years and a median of 52 years. There is a slight preponderance of the condition among men $(\mathrm{m}: \mathrm{f}=3: 2)$. Inflammatory fibroid polyp is a relatively rare condition.

The polyp is obstructive, and symptomatology is determined by its site. In the oesophagus it causes dysphagia, in the stomach pyloric obstruction, and in the small bowel very often intussusception, which is the most common presentation in children. The peripheral blood shows no eosinophilia, and there is no predilection for subjects with allergic traits. The radiological appearances are those of a smooth spherical or hemispherical intraluminal mass, possibly superimposed on intussusception.

Inflammatory fibroid polyps are most often found in the gastric antrum (about $70 \%$ of cases) with the small bowel as the next most common site (about $20 \%$ of cases). Only occasional examples have been 
Table No of cases related to age (in years per decade)

\begin{tabular}{|c|c|c|c|c|c|c|c|c|c|c|}
\hline & \multicolumn{10}{|c|}{ Decade } \\
\hline & $0-9$ & $10-19$ & $20-29$ & $30-39$ & $40-49$ & $50-59$ & $60-69$ & $70-79$ & $80-89$ & $90-99$ \\
\hline $\begin{array}{l}\text { Inflammatory fibroid } \\
\text { polyp }(\mathrm{n}=101)^{*}\end{array}$ & 2 & 2 & $4(2)$ & $3(2)$ & $10(1)$ & $28(4)$ & $18(2)$ & $16(2)$ & $2(1)$ & 2 \\
\hline $\begin{array}{l}\text { Eosinophilic } \\
\text { gastroenteritis } \\
(\mathrm{n}=61) \dagger\end{array}$ & 0 & 3 & $14(1)$ & 11 & $8(1)$ & $17(2)$ & $2(1)$ & 1 & 0 & 0 \\
\hline
\end{tabular}

Numbers in parentheses are cases seen by the authors, ${ }^{*} 14$ cases of inflammatory fibroid polyp; $\dagger$ and five cases of eosinophilic gastroenteritis.

recorded in the oesophagus ${ }^{10}$ and the large bowel. ${ }^{2}$ Macroscopically, the lesion forms a smooth sessile or sometimes pedunculated polyp, usually between $2-5 \mathrm{~cm}$ in diameter (range $0.7-19.5 \mathrm{~cm}$ ) (Fig. 1). The mucosal surface is ulcerated, at least over the apex, and some examples have a central apical fissure, so that a smooth muscle tumour may be simulated radiologically or endoscopically. The colour of the cut surface is pale brown to pink. The polyp arises from the submucosal region and projects into the lumen of the bowel. The muscle coats may be interrupted and the lesion may have a serosal component giving it a shape like a dumb bell.

Microscopically, the inflammatory fibroid polyp

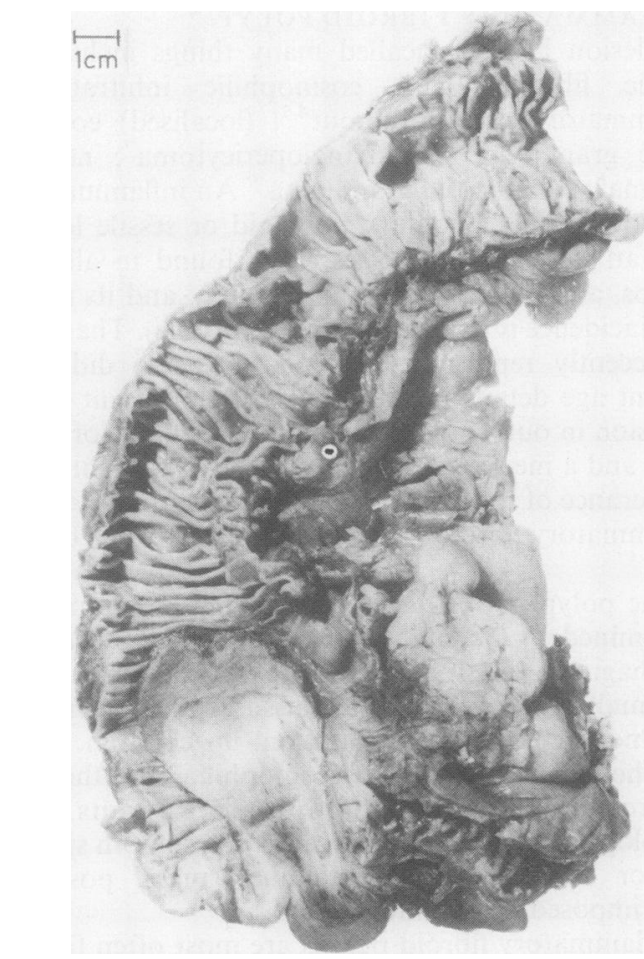

Fig. 1 Inflammatory fibroid polyp of caecum in right hemicolectomy specimen. Lesion originally misdiagnosed as smooth muscle tumour. has a distinctive appearance with a stroma that has been likened to exuberant granulation tissue (Fig. 2). Loose fascicles and whorls of proliferating fibroblasts surround arborising capillaries. Concentric arrangements of fibroblasts, which may show considerable mitotic activity and even cellular atypia around arteriolar cores, have given rise to the erroneous impression that this lesion is a haemangiopericytoma, and this is despite the fact that perivascular concentric whorls of tumour cells are not a classic feature of haemangiopericytoma; neither was mentioned or illustrated by Enzinger. ${ }^{11}$

Characteristically, the stroma is infiltrated by eosinophils to a varying degree, often to a great

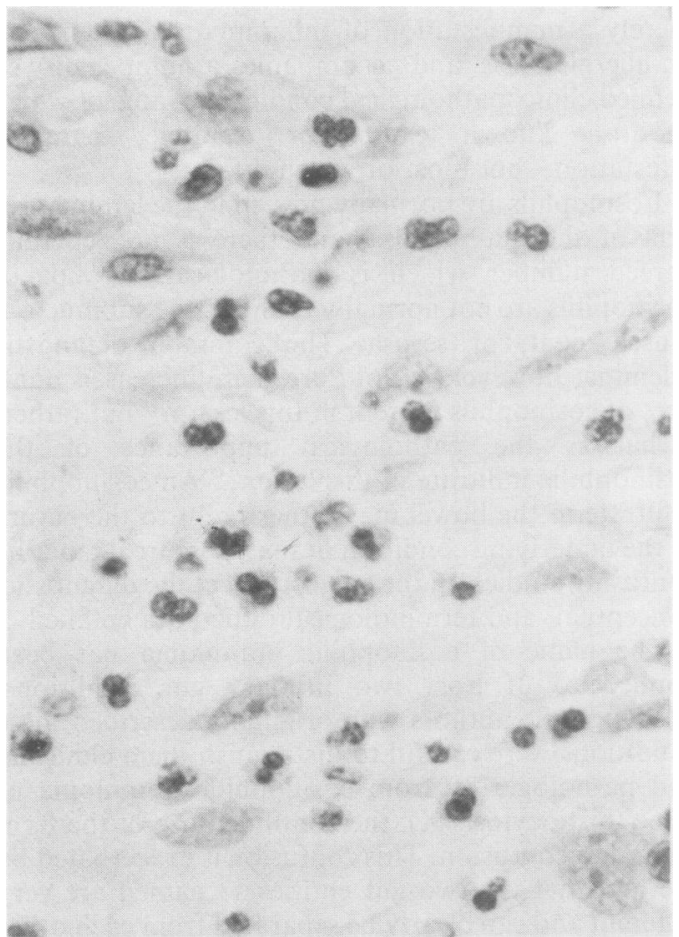

Fig. 2 Inflammatory fibroid polyp (section of lesion in Fig.1) granulation type tissue with loosely collagenous stroma diffusely infiltrated by eosinophils. (Haematoxylin and eosin.) $\times 550$. 
extent. The stroma is usually loosely collagenous or frankly myxoid. Other inflammatory cells such as plasma cells are present and occasional examples of this condition are seen with a clinically unimportant eosinophilic infiltrate and a predominance of plasma cells. Inflammatory granulation tissue infiltrates the submucosa and mucosa to some extent at the margin of the polyp. Granulomas in the proper sense are not a component of the inflammatory fibroid polyp.

$\mathrm{Salm}^{8}$ regarded this lesion as a fibroma - that is, a true neoplasm - but it has little resemblance to any of the soft tissue tumours, which claim a derivation from fibroblasts. There is no evidence to suggest that it is a vascular tumour, and recurrence or metastasis (commonly seen with true haemangiopericytoma) has not been reported. Similarly, there is no good evidence to indicate a neuromatous origin. The generally accepted view is that inflammatory fibroid polyp represents a florid overgrowth of a peculiar type of granulation tissue largely confined to the gastrointestinal tract.

\section{EOSINOPHILIC GASTROENTERITIS}

This rare condition has also been called eosinophilic granuloma (diffuse) and various other names. ${ }^{12}$ There is a slight preponderance of the condition among men ( $\mathrm{m}: \mathrm{f}=3: 2$ ), and the disease seems to have a bimodal age distribution with peaks in the third and sixth decades (Table). This may indicate heterogeneity within a group of conditions rather than a single entity. The age distribution of this condition should be compared with that of inflammatory fibroid polyp (Table). Symptoms are usually those to be expected with pyloric or upper small bowel obstruction but are of quite variable duration (a few months to several years), and there is often a history of recurrent attacks. Most patients $(70 \%)$ have a personal and family history of allergic disorders such as asthma, hay fever, and hypersensitivity to drugs. In some cases intolerance of a particular item of diet (onions, ${ }^{13}$ chocolate ${ }^{14}$ ) is noted. A recent report suggested that there was a subgroup of patients with eosinophilic gastroenteritis associated with connective tissue diseases. ${ }^{15} \mathrm{~A}$ fairly constant finding is peripheral blood eosinophilia (more than $90 \%$ of patients), which may reach counts of $16 \times 10^{9} / 1,12$ and is usually in excess of $1 \times 10^{9} / 1$ (normal $<0.5 \times$ $\left.10^{9} / 1\right)$. The erythrocyte sedimentation rate is usually normal or only moderately raised. Associated clinical features in some cases include peripheral oedema due to enteric protein loss, iron deficiency anaemia, and malabsorption. ${ }^{1617}$

The radiological findings are characteristic and, together with an allergic history and peripheral blood eosinophilia, should allow the diagnosis to be made without recourse to surgery. This was suggested as long ago as $1964^{18}$ and has been reiterated several times. ${ }^{1920}$ Barium meal and follow through show a variable degree of antral stenosis with mucosal irregularity and "pseudopolyposis" when the stomach is affected, as it generally is. Crohn's disease or gastric malignancy may be simulated. In the small intestine thickened mucosal folds are seen, principally due to oedema; these are sometimes sufficient to cause obstruction.

Typically, the gastric antrum is affected (about $70 \%$ of cases); almost always the contiguous upper small bowel. Sometimes the small bowel alone is affected $^{12}$ and, exceptionally, the colon. ${ }^{1221}$ The affected portion of bowel is thickened and rigid due to oedema, and there may be associated ascites with large numbers of eosinophils in the fluid. The mucosal pattern is distorted or obliterated but without extensive ulceration. Mesenteric lymph nodes may be enlarged.

Microscopically intense oedema mainly affecting the submucosa is confirmed, and there is variable diffuse eosinophilic infiltration, usually to a striking degree, that is also predominantly in the submucosa (Fig. 3). The mucosa may appear normal or contain excess eosinophils in the lamina propria. Preponderance of the eosinophils in a particular coat of the bowel-for example, submucosal, serosal-has been the basis of proposed subclassification, ${ }^{1822}$ but this relates to the clinical features only in that eosinophilic ascites occurs when serosal infiltration is extensive. Angiitis and the selective concentration of eosinophils around vessels is not, in our experience, a feature of this disorder. Adjacent lymph nodes show reactive appearances, sometimes with eosinophilic infiltration of the pulp.

The cause of most cases of eosinophilic gastroenteritis is unknown, although an allergic basis seems most likely. Various antigens presented systemically or locally within the alimentary tract may be responsible. The finding of roundworm larvae in the specimens of 12 cases from around Rotterdam in Holland $^{23}$ led to the suggestion that this might be the cause, but clearly this is not true of many cases. The worm found in the above cases and in occasional subsequent cases in the United Kingdom ${ }^{24}$ was a herring parasite, Eustoma rotundatum. The symptoms occur after ingesting raw or lightly salted herrings (roll mops) containing the larvae of the parasite. Presumably repeated exposure to the worm is required for sensitisation to occur.

Due to the sprue like symptoms and a case of eosinophilic gastroenteritis accompanied by enteropathy induced by gluten and dermatitis herpetiformis, ${ }^{25}$ gluten has been suggested as a possible allergen. In other patients dietary components such as beef extract have been shown to induce relevant 


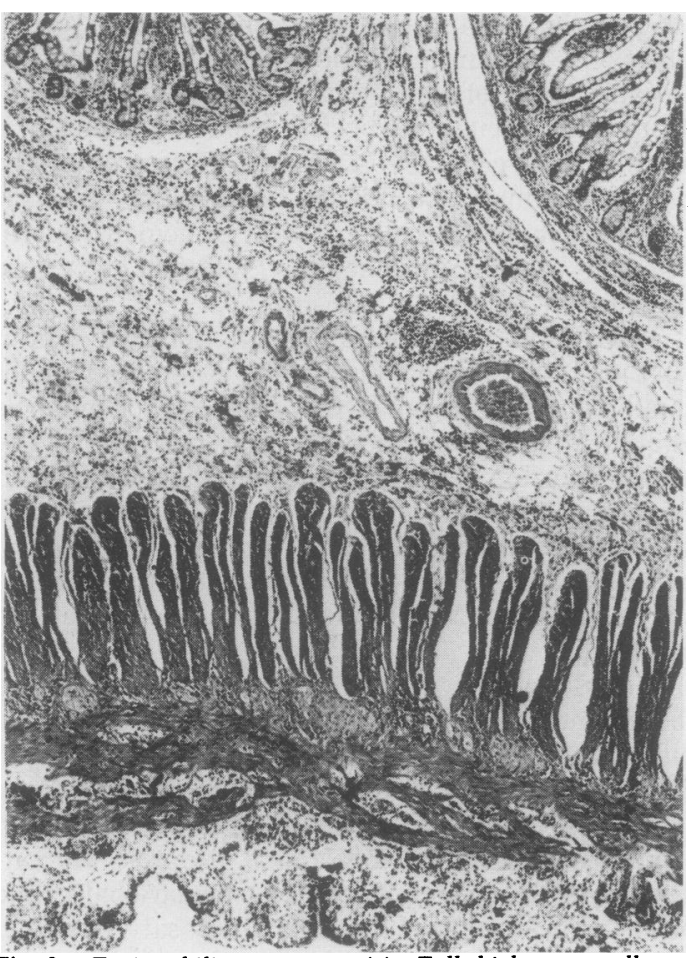

Fig. 3 Eosinophilic gastroenteritis. Full thickness small bowel with oedematous thickening and inflammation of all layers, particularly submucosa. Inflammatory cells are almost exclusively eosinophils. (Haematoxylin and eosin.) $\times 35$.

symptoms and eosinophilic infiltration in jejunal biopsy. ${ }^{22}$ Not all authors, however, are keen to attribute the cause of eosinophilic gastroenteritis to simple food allergy. Leinbach and Rubin could produce appropriate symptoms in their patient with eosinophilic gastroenteritis when soya bean or steak challenges were given, but they could not detect tissue eosinophilia in jejunal biopsies associated with the food challenges. ${ }^{26}$

Intolerance of cow's milk protein in children seems to be a different but related condition in patients allergic to cow's milk protein. Malabsorption and loss of enteric protein are occasionally also manifested in this condition. It has now been established that most children with intolerance to cow's milk protein have an enteropathy - that is, an abnormal small intestinal mucosa under light microscopy, ${ }^{27}$ but whether or not there is a considerable increase in eosinophils in the mucosa of the small intestine in this particular type of enteropathy has not been agreed. Some authors have found mucosal eosinophilia in most of their patients in response to a milk challenge ${ }^{28}$ while others have not. ${ }^{29} \mathrm{~A}$ recent meticulous quantitative study could find no substantial increase in numbers of eosinophils in the lamina propria of children with cow's milk $\stackrel{0}{\vec{\circ}}$ sensitive enteropathy before and after a milk chal- 은 lenge, but did find a substantial increase in intra- $\vec{F}$ epithelial eosinophils after the challenge. ${ }^{27}$ The treatment of this enteropathy is, of course, to remove cow's milk protein from the diet.

The ideal treatment of eosinophilic gastroenteritis $\frac{\bar{D}}{\bar{D}}$ is to identify and remove the allergen from the diet, $\stackrel{\varrho}{\Omega}$ but this can be done only rarely. Fortunately, adre- $ळ$ nocorticosteroids are very effective and have a strong $\overrightarrow{0}$ eosinopenic action. Radiologically obvious lesions resolve after treatment with steroids, and it is worth $\vec{\omega}$ repeating that surgery is not indicated in a patient with a radiologically typical lesion, ${ }^{18-20}$ a history of allergy, and a peripheral blood eosinophilia. Anti- w histamines are of little benefit. The long term progno- sis for this condition is good.

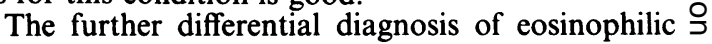
infiltration of the bowel includes the following dis- $\overrightarrow{ }$ orders:

Polyarteritis nodosa The gastrointestinal tract is often affected (up to $25 \%$ of cases). The radiological appearances of mucosal thickening due to oedema are $\vec{\theta}$ similar to eosinophilic gastroenteritis, and a peripheral blood eosinophilia is often seen. The erythrocyte sedimentation rate is generally considerably increased, and other manifestations of the disease for example, arthropathy, central nervous system $\bar{\partial}$ signs-are often present. Although there may be a 0 history of sensitivity for drugs, there is not usually a $\stackrel{\mathbb{Q}}{2}$ strong association with allergic traits. Micro- $\overrightarrow{\overrightarrow{0}}$ scopically, there is an arteritis and sometimes tissue 3 eosinophilia. ${ }^{30}$ Associated ischaemic changes in the gut mucosa do not prove that an eosinophilic infiltrate is part of polyarteritis nodosa-for example, the ulceration seen in association with gut lymphoma (with or without large numbers of eosinophils) is 3 often mediated through ischaemia after small blood vessel walls have been invaded by tumour cells and $\frac{\rho}{3}$ thrombosis ensues.

Crohn's disease Although eosinophils may be 은 numerous, particularly in the bowel mucosa, the $\frac{7}{0}$ other microscopic features of Crohn's disease are quite unlike eosinophilic gastroenteritis. Confusion is $\mathrm{N}$ only likely on gross appearances and radiological findings, especially in disease confined to the small 0 bowel. The associated clinical features of eosinophilic $\omega$ gastroenteritis are not present.

Parasitic infestations of the gut Though these are relatively uncommon in the United Kingdom, they should always be considered when eosinophils are a conspicuous feature of an inflammatory reaction. The $\frac{0}{0}$ causative agent can often be recognised histologically. $\frac{O}{\mathbb{D}}$ The eggs of Shistosoma mansoni and less often $S$ hae- $\frac{?}{\mathbb{D}}$ matobium and $S$ japonicum can be identified in large $\stackrel{\mathbb{Q}}{\varrho}$ and small bowel biopsies and are sometimes, 
although not always, associated with a dense eosinophil infiltrate. Other parasites, which are sometimes associated with dense eosinophilia in the lamina propria of the jejunum, are Giardia lamblia and hookworms. G. lamblia can most easily be identified in sections as sickle shaped bodies with basophilic cytoplasm often attached to the mucosal surface, rather than the classically described roughly triangular organisms with two nuclei. Hookworms are most often indicated in sections by erosions or circular channels where the worm has been lying in relation to these in the densest aggregates of eosinophils.

Carcinoma of gastric antrum Extension of carcinoma into contiguous duodenum and jejunum is highly unusual, unlike eosinophilic gastroenteritis. Gastric carcinoma is not normally accompanied by an allergic history or blood eosinophilia (present only in about $1 \%$ of cases). Gastric infiltration by eosinophils, however, may be intense and sufficient to obscure an underlying carcinoma of linitis plastica type. ${ }^{31}$

Granulomatous gastritis $^{32}$ This is probably another heterogeneous group of disorders with a common microscopic inflammatory response to various foreign agents. An allergic type of hypersensitivity is not manifested, and the disorder is confined to the stomach. Eosinophils are generally not a conspicuous component of the inflammatory reaction, which combines sarcoid like granulomas and variable numbers of lymphocytes in the mucosa. The diagnosis depends on the exclusion of specific granulomatous conditions.

Hereditary angioneurotic oedema $a^{33}$ This causes recurrent attacks of intestinal obstruction due to oedema. The stomach is not affected to any great extent. Blood or tissue eosinophilia is not a feature, but victims of this condition may appear allergic. The cause is deficiency of $\mathrm{Cl}$ esterase inhibitor and the treatment of severe attacks by fresh frozen plasma.

Systemic mastocytosis ${ }^{34}$ This is a rare condition that may be associated with blood and tissue eosinophilia, can cause intestinal oedema (urticaria of the bowel), and produce a sprue like clinical picture. Infiltration of the bowel by mast cells is usually most intense in the submucosa and serosa, so that mucosal biopsy may show only mild eosinophilic infiltration. There are almost always cutaneous manifestations (urticaria pigmentosa) in this condition. A syndrome similar to the carcinoid syndrome with wheezing, erythematous flush, and diarrhoea may be caused by excess release of histamine.

Hypereosinophilic syndrome ${ }^{35}$ This term, as currently used on both sides of the Atlantic, refers to a condition characterised by persistent and prolonged hypereosinophilia of the peripheral blood with prominent widespread damage to several organs particu- larly heart, lungs, brain, and to a lesser extent, liver, gastrointestinal tract, skin and kidneys. There is an appreciable mortality in this disorder, with only $50 \%$ of patients surviving four years or longer. We have never seen it present primarily with gut lesions, but if this were to occur the syndrome could probably only be differentiated from eosinophilic gastroenteritis on the basis of its different extragastrointestinal features. Histiocytosis $X$ Gastrointestinal spread in this group of conditions is exceedingly rare. The key reference in gastrointestinal disease in histiocytosis $\mathrm{X}$ undoubtedly describes a rare malignant histocytic or lymphomatous condition affecting the bowel of children, ${ }^{36}$ but the published illustrations and histological description of pronounced mitotic activity in the infiltrating cells lead us to doubt whether this is really as currently perceived histiocytosis $X$. The precise origin of the "tumour cell" in histiocytosis X is still hotly debated, but it seems, based on electron microscopic and immunohistochemical studies, to relate most closely to the Langerhans' cell in the skin or the interdigitating reticulum cell of the Tzones of lymph nodes, or both. The best ultrastructural marker of the

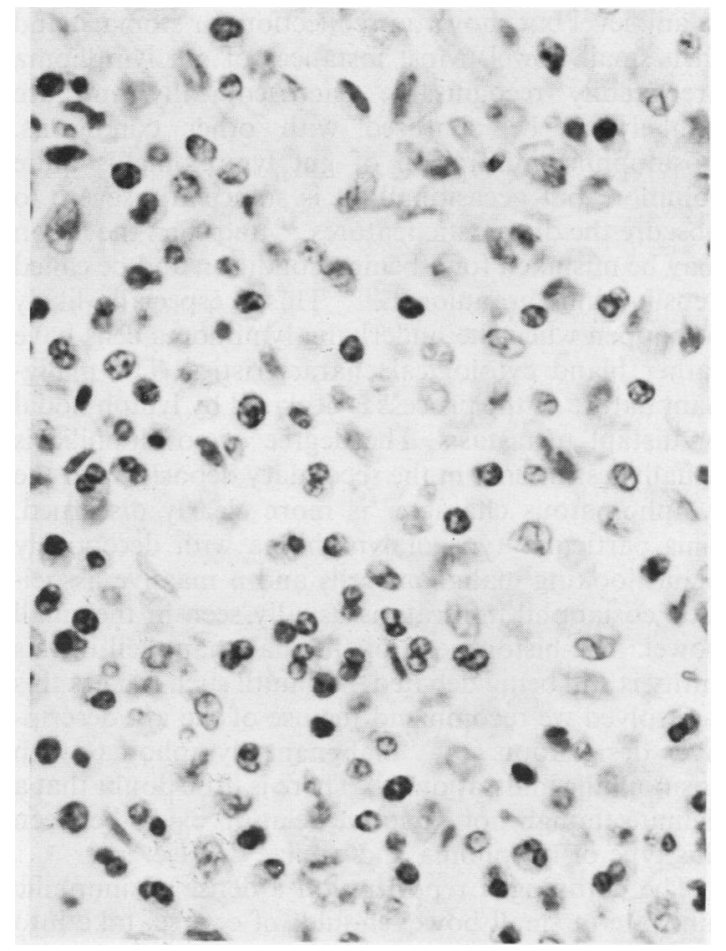

Fig. 4 Histocytosis $X$. Submucosal large bowel infiltrate, an admixture of inflammatory cells (mostly eosinophils), and histicytoid cells (larger, with irregularly shaped paler nuclei, abundant pale cytoplasm, but no mitoses). (Haematoxylin and eosin.) $\times 550$. 
tumour cell is the so called Birbeck granule which presents a rod, flask, or tennis racket shaped appearance with an internal paracrystalline lattice. ${ }^{37} \mathrm{We}$ have only ever seen gastrointestinal spread by histiocytosis $\mathrm{X}$ in one patient: a woman, aged 65 at death, with diabetes insipidus and multifocal histiocytosis $\mathrm{X}$ known to have been present for several years. Necropsy, performed within two hours of death (by AJB) showed multiple scattered areas of ulceration throughout the colon but not in the rectum. The remainder of the bowel was unremarkable. Histology showed each ulcer to be centred on a focus of infiltration bỳ typical histiocytosis $X$ (Fig. 4). The number of eosinophils present in these lesions was extremely variable, both within individual lesions and from lesion to lesion. The infiltrate seemed to be centred on the submucosa. Gastrointestinal symptoms had not latterly been a prominent feature of her illness, but she had had alternating bouts of constipation and diarrhoea, and radiological "strictures" had been noted in the colon. Malignant lymphoma with eosinophilic infiltration Malignant lymphoma is an uncommon primary tumour in the alimentary tract. It may occur at any level but shows a predilection for stomach and then small bowel. Most instances of gut lymphoma are readily recognisable microscopically and are unlikely to be confused with other conditions. Eosinophilic infiltration of gut lymphoma is quite common, but occasionally it is sufficiently severe to obscure the diagnostic features, ${ }^{38}$ and then the lesion may be mistaken for a benign condition and be called "eosinophilic granuloma." 39 This is especially likely to happen when the underlying lymphoma cells have rather bland cytological characteristics. The malignant nature of the process is declared by lymph nodal or distant metastasis. The degree of eosinophilia is usually less intense in the secondary deposits, and the lymphomatous character is more clearly discerned. This particular type of lymphoma with deceptively bland looking malignant cells and a massive associated eosinophil infiltrate is usually seen in the small bowel. The histogenesis of the malignant cell in this entity is still being debated, and until such time as this is resolved we recommend the use of the apt descriptive designation of "malignant lymphoma with eosinophilic infiltration." ${ }^{38}$ There is little doubt that a definite though not exclusive relation exists between this type of lymphoma and coeliac disease.

The pathologist reporting on a dense eosinophilic infiltrate in small bowel should, of course, take into account other clues as to its importance-for example, known coeliac disease, or subtotal villous atrophy, or gastric metaplasia in adjacent mucosa-all of which increase the likelihood that a dense infiltrate is coeliac related and therefore possibly lymphomatous, even if atypical cells are very hard to find among masses of eosinophils. Primary Hodgkin's disease of $\underline{0}$ the gut is extremely rare; many alleged cases, in fact, are other forms of lymphomas, including "malignant lymphoma with eosinophilic infiltration." 38

Eosinophilic infiltration in such lesions and in the occasional gastric and colonic carcinoma, or smooth muscle tumour may represent an immunological (allergic) response by the host to tumour neoantigens. Thus neoplasia may represent just one of many possible antigens causing an eosinophilic response, which in one degree or another is such a common occurrence in gastrointestinal pathology.

We thank Miss Caroline Judge for her customary good humoured secretarial help; the department of medical illustration, St Bartholomew's Hospital; $\mathbf{M r}$ P Crocker, Mrs Dawn O'Keefe, and Mr J Hopwood for photographic help.

\section{References}

${ }^{1}$ Johnstone JM, Morson BC. Inflammatory fibroid polyp of the gastrointestinal tract. Histopathology 197.8;2:349-61.

${ }^{2}$ Shimer GR, Helwig EB. Inflammatory fibroid polyps of the intestine. Am J Clin Pathol 1984;81:708-14.

${ }^{3}$ Salm R. Gastric fibroma with eosinophilic infiltration. Gut 1965;6:85-91.

${ }^{4}$ Campbell WL, Green WM, Seaman WB. Inflammatory pseudotumour of the small intestine. Am J Roentgenol Radium Ther Nuc Med 1974;121:305-11.

${ }^{5}$ Livolsi VA, Perzin KA. Inflammatory pseudotumours (inflammatory fibrous polyps) of the small intestine: a clinicopathologic study. Am J Digest Dis 1975;20:475-81.

${ }^{6}$ Toole HJ. Moschopoulos AN. Eosinophilic granuloma of the gastrointestinal tract. Br J Surg 1959;46:445-8.

${ }^{7}$ Olsen EGJ, Wellwood JM. Haemangiopericytoma of the small intestine. Br J Surg 1970;57:66-9.

${ }^{8}$ Shubin H, Sargent JA. Gastric neurofibromas simulating granulomas. AMA Arch Pathol 1955;60:286-8.

${ }^{9}$ Vanek J. Gastric submucosal granuloma with eosinophilic infiltration. Am J Pathol 1949;25:397-407.

${ }^{10}$ Leand PM, Murray GF, Zuidema GD, Shelley WM. Obstructing oesophageal polyp with eosinophilic infiltration. So called eosinophilic granuloma. Am J Surg 1968;116:93-6.

${ }^{11}$ Enzinger FM, Weiss SW. Soft tissue tumours. Toronto: CV 윽 Mosby, 1983:463-81.

12 Johnstone JM, Morson BC. Eosinophilic gastroenteritis. Histopathology 1978;2:335-48.

${ }^{13}$ Kaijser R. Zur Kerintnis der allergischen Affektionen des $\mathrm{N}$ Verdauungs-Kanals vom Standprunkt des Chirurgen aus. o Archiv für Klinische Chirurgie 1937;188:36-64.

${ }^{14}$ Orr IM, Miller AA, Russell JYW. Eosinophilic infiltration of the stomach and bowel. Postgrad Med J 1954;30:485-93.

${ }^{15}$ De Schryver-Kecskemeti K, Clouse RE. A previously $\sigma$ unrecognised subgroup of "eosinophilic gastroenteritis". Association with connective tissue diseases. Am J Surg Pathol 1984;8:171-80.

${ }^{16}$ Greenberger NJ, Tennenbaum JI, Ruppert RD. Protein-losing enteropathy associated with gastrointestinal allergy. Am J Med 1967;43:777-84.

${ }^{17}$ Kaplan SM, Goldstein F, Kowlessar OD. Eosinophilic gastroenteritis. Report of a case with malabsorption and proter -rosing enteropathy. Gastroenterology 1970;58:540-5.

${ }^{18}$ Eidelman MJ, March JL. Eosinophilic gastroenteritis. Am J

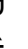


Roentgenol Radium Ther Nuc Med 1964;91:773-8.

${ }^{19}$ Burhenne HJ, Carbone JV. Eosinophilic (allergic) gastroenteritis. Am J Roentgenol Radium Ther Nuc Med 1966;96:332-8.

${ }^{20}$ Goldberg HI, O'Kieffe D, Jenis EH, Boyce HW. Diffuse eosinophilic gastroenteritis. Am J Roentgenol Radium Ther Nuc Med 1973;119:342-51.

${ }^{21}$ Dunstone GH. A case of eosinophilic colitis. Br J Surg 1959;46:474-6.

${ }^{22}$ Klein NC, Hargrove RL, Sleisenger MH, Jeffries GH. Eosinophilic gastroenteritis. Medicine 1970;49:299-319.

${ }^{23}$ Kuipers FC, van Thiel PH, Rodenberg W, Wielings WJ, Roskam RTH. Eosinophilic phlegmon of the alimentary canal caused by a worm. Lancet 1960;ii:1171-3.

${ }^{24}$ Ashby BS, Appleton PJ, Dawson IMP. Eosinophilic granuloma of gastrointestinal tract caused by herring parasite Eustoma rotundatum. Br Med J 1964;i:1141-5.

${ }^{25}$ Bennett RA, Whitelock T 3d, Kelley JL Jr. Eosinophilic gastroenteritis, gluten enteropathy and dermatitis herpetiformis $\mathrm{Am} \mathrm{J}$ Dig Dis 1974;19:1154-61.

${ }^{26}$ Leinbach GE, Rubin CE. Eosinophilic gastroenteritis-a simple reaction to food allergens? Gastroenterology 1970;59:874-89.

${ }^{27}$ Makenda C, Phillips AD, Briddon A, Walker-Smith JA. Quantitative analysis of small intestinal mucosa in cow's milk sensitive enteropathy. J Pediatr Gastrenterol Nutr 1984;3:349-56.

${ }^{28}$ Withrington R, Challacombe DN. Eosinophil counts in duodenal tissue in cow's milk allergy. Lancet 1979;i:675.

${ }^{29}$ Sarilahti E, McCalla R, Perkkio M, Kuitinen P, Backman A Eosinophils in cow's milk allergy. Lancet 1979;i:1198.
${ }^{30}$ Morson BC, Dawson IMP. Gastrointestinal pathology. 2nd ed. Oxford: Blackwell Scientific Publications, 1979:115:604-5.

${ }^{31}$ Burkhart CR, Wilkinson RH. Inflammatory pseudotumours of the stomach. Cancer 1968;21:1052-4.

${ }^{32}$ Morson BC, Dawson IMP. Gastrointestinal pathology. 2nd ed. Oxford: Blackwell Scientific Publications, 1979:114.

${ }^{33}$ Roitt IM. Essential immunology. 5th ed. Oxford: Blackwell Scientific Publications, 1984:174.

${ }^{34}$ Ammann RW, Vetter D, Dehyle P, Tschen H, Subser H, Schmid M. Gastrointestinal involvement in systemic mastocytosis. Gut 1976;17:107-12.

${ }^{35}$ Chusid MJ, Dale DC, West BC, Wolf SM. The hypereosinophilic syndrome. Analysis of fourteen cases with review of the literature. Medicine 1975;54:1-27.

${ }^{36}$ Keeling JW, Harries JT. Intestinal malabsorption in infants with histiocytosis X. Arch Dis Child 1973;48:350-4.

${ }^{37}$ Ghadially FM. Diagnostic electron microscopy of tumours. London: Butterworths, 1980:237-42.

${ }^{38}$ Blackshaw AJ. Non-Hodgkin's lymphomas of the gut. In: Wright $\mathrm{R}$, ed. Recent advances in gastrointestinal pathology. WB Sanders Co, 1980:213-40.

${ }^{39}$ McDonald GSA, Hourihane DOB. Malignant lymphoma mimicking eosinophilic granuloma of the gut. Irish $\mathrm{J} \mathrm{Med} \mathrm{Sci}$ 1974;143:168-75.

Requests for reprints to: Dr DA Levison, Department of Histopathology, St Bartholomew's Hospital, West Smithfield, London EC1A 7BE, England. 